\title{
Broadbanding of Circular Patch Antenna using Stacked Multi Resonator Configuration
}

\author{
Er. Deeksha Singh ${ }^{1}$, Dr. Dushyant Singh ${ }^{2}$ \\ ${ }^{1,2}$ (Department of Electronics \& Communication Engg, RBS ETC, Bichpuri, Agra, India)
}

\begin{abstract}
In the following paper, a stacked multiresonator configuration of a circular patch antenna using FR4 material as a substrate with dielectric constant of 4.2, for resonant frequency of $2 \mathrm{GHz}$ is proposed. In this configuration, there is hybridization of two techniques, the stacking technique and the multiresonator technique. The radius of the patch is calculated to be $17.8 \mathrm{~mm} \&$ the air gap is $15 \mathrm{~mm}$ between the upper and the lower layer. The percentage bandwidth is $4.6 \%$.
\end{abstract}

Keyword: Stacked, Multiresonator

\section{Introduction}

Nowadays, the microstrip antenna is an established type of antenna that is confidently suggested by designers all over the world, particularly when low-profile radiators are in high demand. The microstrip, or printed, antenna has now achieved an age of maturity where many well tested techniques can be relied upon and there are few interesting facts about its behavior.

The invention of the microstrip-antenna concept has been attributed to many sources and the earliest include Greig and Englemann [1] and Deschamp [2]. At that time period, there was the emission of unwanted radiation from the then new thin strip line circuits, which was well appreciated and simultaneously the dimensions of the substrate and conducting strip were reduced to inhibit the radiation effects, from all of this 'microstrip' is created.

In the simplest form of microstrip antenna, there is a radiating patch on one side of dielectric substrate and ground plane on other side. Microstrip Patch Antennas are popular for their well-known feature, such as a low profile, light weight, and compatibility with Monolithic Microwave Integrated Circuits (MMICs). In the modern communication system, Such as those for satellite links (GPS, Vehicular, etc.), as well as emerging applications, such as Wireless Local Networks (WLAN), offer such antennas with compatibility and low-cost. Conventional microstrip patch antennas has some disadvantages of low efficiency, narrow bandwidth (3-6)\% $[1,2]$ of the central frequency, its bandwidth is limited to a few percentage which is not enough for most of the wireless communication system[3]. There are several designs have been investigated and suggested to decrease the size of antenna [4] and to improve the bandwidth of antenna[5,6].

\section{Antenna Structure}

An MSA in its simplest form consists of a radiating patch on one side of a dielectric substrate and a ground plane on the other side. The top and side views of a Circular MSA (CMSA) are shown in Figure1. The radiating patch and the feed lines are usually photo etched on the dielectric substrate. For simplicity of analysis, the patch is generally square, rectangle, circular, triangle and elliptical or some other shape.

For a rectangular patch, the length $\mathrm{L}$ of the patch is usually in the range of $0.3333 \lambda_{0}<<0.5 \lambda_{0}$, where $\lambda_{0}$ is the free space wavelength. The patch is selected to be very thin such that $t<<0$ (where $t$ is the patch thickness).The height $\mathrm{h}$ of the substrate is usually $0.003 \lambda_{0}$ to $0.05 \lambda_{0}$. The dielectric constant [10] of the substrate $€ \mathrm{r}$ is typically 4.22 .

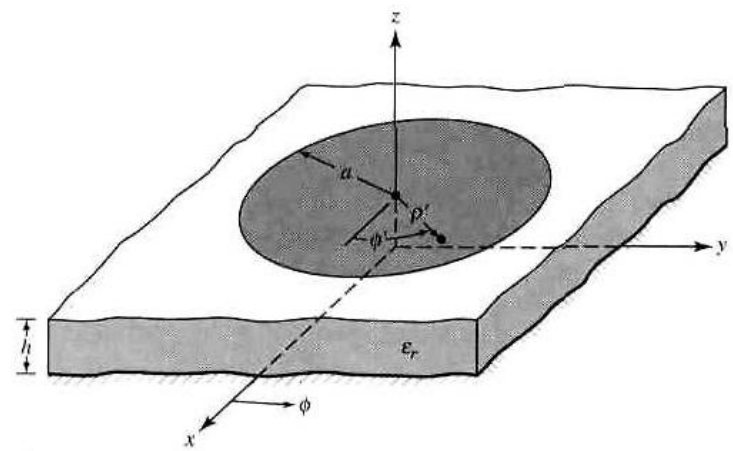

Fig 1: Circular Patch Microstrip Antenna 
For a rectangular patch, the length $L$ of the patch is usually in the range of $0.3333 \lambda_{0}<<0.5 \lambda_{0}$, where $\lambda_{0}$ is the free space wavelength. The patch is selected to be very thin such that $t<<0$ (where $t$ is the patch thickness).The height $h$ of the substrate is usually $0.003 \lambda_{0}$ to $0.05 \lambda_{0}$. The dielectric constant [10] of the substrate $€ \mathrm{r}$ is typically 4.22 .

\section{Design of Suggested Antenna}

We begin the design process of Stacked Multiresonator Circular Patch Microstrip Antenna by designing a reference antenna using IE3D software for the simulation. Considering the result of the reference antenna as basis we try to increase the bandwidth of the antenna using Stacked Multiresonator configuration.

\subsection{Reference Antenna Configuration}

In the following fig 3, a simulated design of reference antenna is shown in which radius "a" $=21 \mathrm{~mm}$ and probe is connected to ( $\mathrm{X}=9, \mathrm{Y}=0$ ). With the help of following equations [8], Radius of the reference antenna is calculated.

$$
\begin{gathered}
a=\frac{F}{\left\{1+\frac{2 h}{\pi \varepsilon_{r} F}\left[\operatorname{In}\left(\frac{\pi F}{2 h}\right)+1.7726\right]\right\}^{\frac{1}{2}}} \\
F=\frac{8.791 \times 10^{9}}{f_{r} \sqrt{\varepsilon_{r}}} \\
F=\frac{8.791 \times 10^{9}}{2 \times 10^{9} \sqrt{4.2}}
\end{gathered}
$$

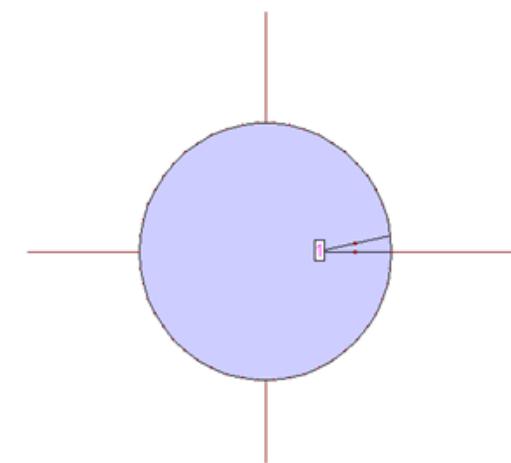

Fig 2: Reference Antenna: 2D Geometry

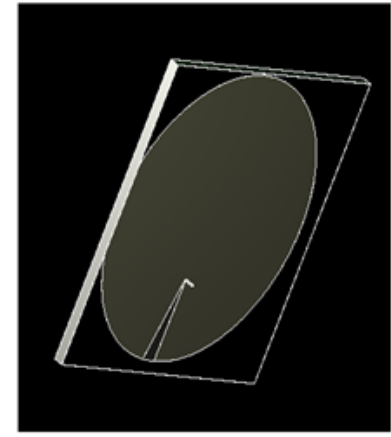

Fig 3: Reference Antenna: 3D Geometry

\subsection{Stacked Multiresonator Configuration}

In this stacked multiresonator configuration, we stacked two layers of microstrip patches in which lower layer includes a ground plane and a circle of radius ' $a$ ' $=17.8 \mathrm{~mm}$ and in the upper layer, there is an identical circle of the lower patch. In this design, air gap of $15 \mathrm{~mm}$ is being taken for stacking. . The probe-feed point for this stub is $(\mathrm{X}=0, \mathrm{Y}=17)$ and radius can be calculated from the earlier mentioned equations.

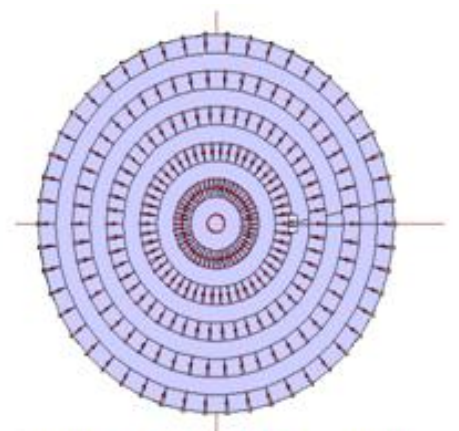

Fig 4: 2D Geometry of Stacked Multiresonator Configuration

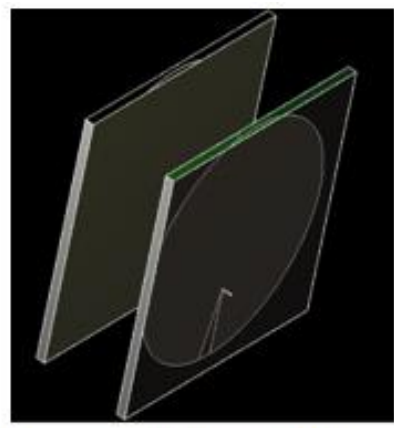

Fig 5: 3D Geometry of StackedMultitesonator configuration 


\section{Simulation Results}

\subsection{Simulation Result of Refrence Antenna}

Fig 6 and Fig 7 show the return loss curve and VSWR curve for the refrence antenna, We find that the return loss is minimum when the feed point coordinates are $(\mathrm{X}=9, \mathrm{Y}=0)$ and the value of the return loss is $20.28 \mathrm{~dB}$ as shown in fig. 4

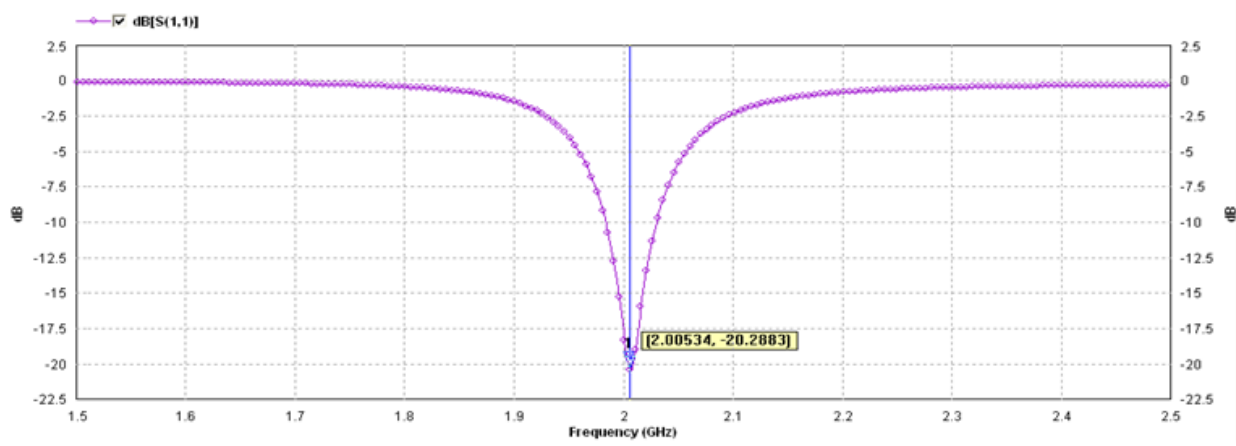

Fig 6: Return Loss Curve for Reference Antenna

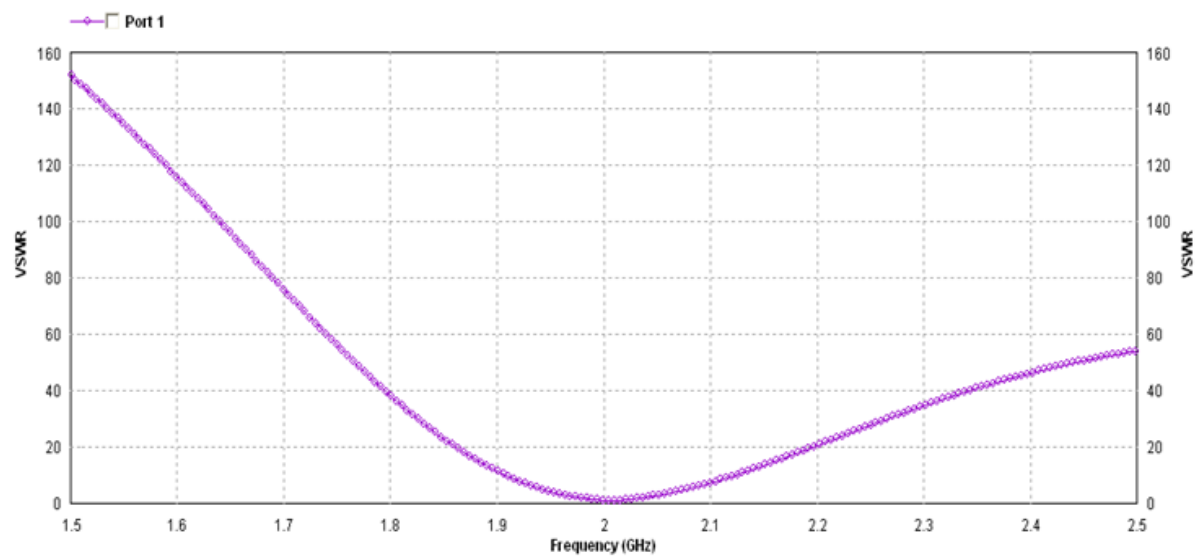

Fig 7: VSWR Curve for Reference Antenna

Fig 8 show the smith chart for the refrence antenna

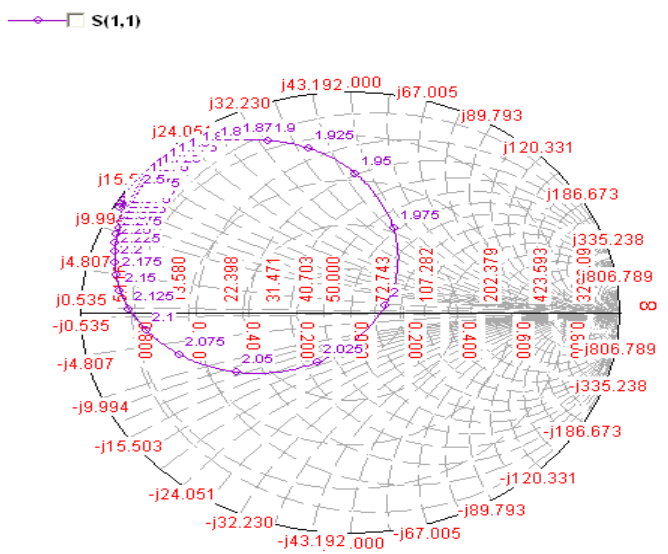

Fig 8: Smith Chart for Reference Antenna

The bandwidth of reference antenna is

$$
\begin{aligned}
\text { Bandwidth }= & f_{2}-f_{1} \\
= & 2.03-1.984 \mathrm{GHz} \\
= & 46 \mathrm{MHz}
\end{aligned}
$$


And the percentage bandwidth is

$$
f_{\text {avg }}=\frac{f_{1}+f_{2}}{2}=2.057 \mathrm{GHz}
$$

$$
\text { Bandwidth \% }=\frac{\frac{f_{2}-f_{1}}{f_{\text {avg }}} \times 100}{=2.29 \%}
$$

Here $f_{1}$ and $f_{2}$ are the lower and the upper cut off frequencies and can be obtained from the return loss graph, and $f_{\text {avg }}$ is the average value of $f_{1}$ and $f_{2}$.

\subsection{Simulation Results of Stacked Multiresonator Configuration}

In this type of configuration, a parasitic element is stacked over a reference patch and this is identical in shape [7], [8]. The height of dielectric plate is $1.6 \mathrm{~mm}$ and the height of air gap [1], [2] is taken $15 \mathrm{~mm}$. After the calculation using equation (1), the radius achieved is ' $a '=17.8 \mathrm{~mm}$. This configuration is simulated at the resonant frequency $2 \mathrm{Ghz}$ using IE3D software. As shown in the following figures, the return loss is $-12.64 \mathrm{~dB}$ and VSWR is shown in the following figures:

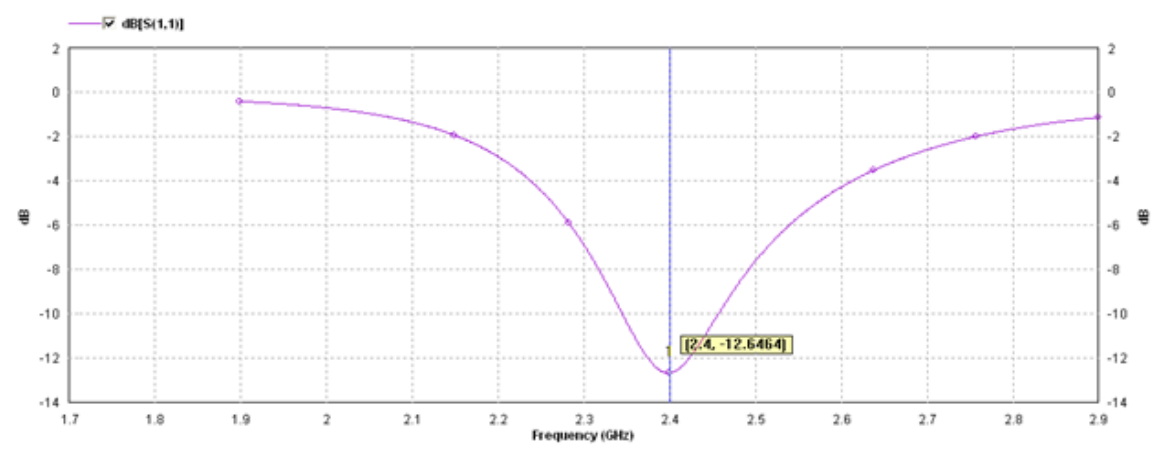

Fig 9: s-parameter curve for stacked multiresonator configuration

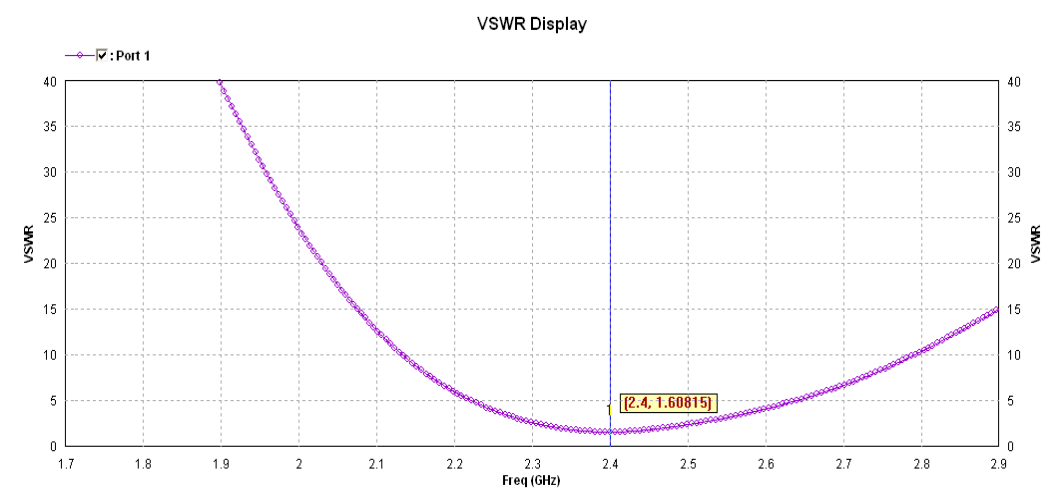

Fig 10: VSWR curve for stacked multiresonator configuration

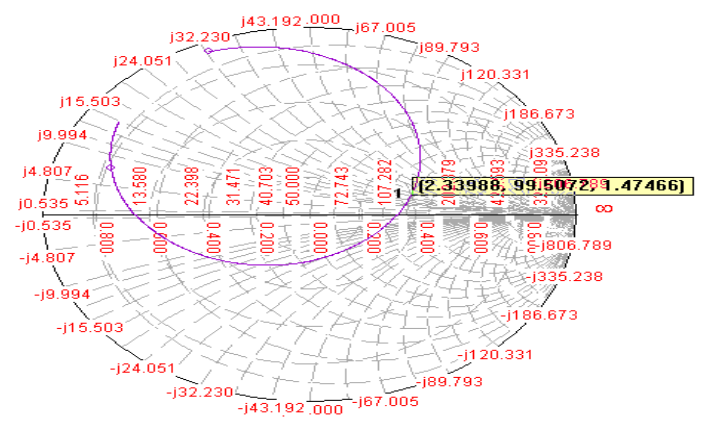

Fig 11: Smith chart for stacked multiresonator configuration 
The bandwidth of the SLSM antenna is calculated from the return loss graph.

$$
\begin{aligned}
& \text { Bandwidth }=f_{2}-f_{1} \\
& =2.457-2.346 \mathrm{GHz} \\
& =111 \mathrm{MHz} \\
& f_{\text {avg }}=\frac{f_{1}+f_{2}}{2}=2.401 \mathrm{GHz}
\end{aligned}
$$

And the percentage bandwidth is

$$
=2.85 \% \quad \text { Bandwidth } \%=\frac{\frac{f_{2}-f_{1}}{f_{\text {avg }}} \times 100}{=4.6 \%}
$$

With the help of the following table, the comparison between the results of reference antenna and SLSC can be explained:

Table 1: Comparison Between Reference Antenna \& Stacked Multiresonator Configuration

\begin{tabular}{|l|l|l|}
\hline Parameters & Single layer reference antenna & Stub Loaded Stacked Antenna \\
\hline Operating freq.(GHz) & $2 \mathrm{GHz}$ & $2.4 \mathrm{GHz}$ \\
\hline Radius & $21 \mathrm{~mm}$ & $17.8 \mathrm{~mm}$ \\
\hline Bandwidth & $46 \mathrm{MHz}$ & $111 \mathrm{MHz}$ \\
\hline Return Loss & $-20.28 \mathrm{~dB}$ & $-12.64 \mathrm{~dB}$ \\
\hline
\end{tabular}

Hence by using Stacked Multiresonator Configuration,the bandwidth of the antenna is enhanced [8].

\section{Conclusions}

The simulation carried out on the proposed stacked antenna configuration had provided a useful design for a circular micro strip antenna with enhanced bandwidth. This technique has its advantages as it does not increase the size of micro strip antenna.

\section{References}

[1]. KURAMOTO M. and SHINJI M.(1986): “ Second Generation Mobile Radio Telephone System in Japan” IEEE Commu. Mag.24, pp 16- 21.

[2]. HORI T. and NAKAJIMA N. (1983): "Sector-beam base station antenna for land mobile communication" Natl. Conv. Rec, IECE Japan 754

[3]. Patil V.P ,"Enhancement of BW of Rectangular Patch Antenna using two square slots techniques," International Journal of Engineering \& Emerging Technology, Oct 2012, ISSN:2231-6604.

[4]. Nashaat DM, Elsadek H,"Miniturized E-shaped dual band PIFA on FR4 Substrates."Radio Science Conference,2006 NRSC 2006 Proceedings of the Twenty Third National.2006;1-6.

[5]. Fujimoto T." "Wideband stacked square microstrip antenna with shorting Plates" IEICE Trans B:Communications.2008 May 1;E91$B(5)$ :

[6]. M. Du Plessis and J. H. Cloete, “Tuning stub for microstrip patch antenna," in Proc. IEEE Antennas Propagat. Symp., June 1993, pp. $964-967$.

[7]. Lin,Row j, "Bandwidth enhancement for dual frequency Micro- Strip antenna with conical radiation".Electronics Letters.2008; 44(1):2-3. 